\title{
Participatory research for sustainable agriculture: the case of the Italian agroecological rice network
}

\author{
Elena Pagliarino ${ }^{1 *}$ (D), Francesca Orlando ${ }^{2}$, Valentina Vaglia ${ }^{2}$, Secondo Rolfo ${ }^{1}$ and Stefano Bocchi ${ }^{2}$
}

\begin{abstract}
Since the Green Revolution, worldwide agriculture has been characterized by a typical top-down approach. The degree of autonomy, creativity, and responsibility of farmers has been limited by the continuous external inputs of chemicals, machinery, advice, subsidies and knowledge.

The issue of sustainability has brought complexity and uncertainty to this mainly linear process of innovation, steering agriculture toward alternative models. Agroecology represents an innovative paradigm of agriculture in which external inputs are minimized, and the assets of the farm are greatly valued. Agroecological production relies on the farmers' direct management of resources and on their active engagement in the agricultural knowledge and innovation system.

This paper focuses on the experience of a group of farmers, scientists, public officials, and managers of private companies who are experimenting with agroecology in rice production in one of the most intensively farmed, profitable and environmentally sensitive areas of Italy. The partnership regularly comes together to discuss agricultural techniques and results, needs, and paths of innovation; in addition, it stimulates and takes part in research projects, following a participatory process based on co-learning and mutual responsibility. By using ethnographic methods such as direct observations and in-depth interviews, our work may contribute to understanding the role of participatory research in sustainable agriculture and what makes for good participation.
\end{abstract}

Keywords: Rice farming, Agroecology, Network, Participatory research, Case study

\section{Introduction}

\section{The traditional model of innovation and its failings}

From the so-called Green Revolution, started in the 1950s, to the current period of innovations based on digital devices, worldwide agriculture has been characterized by a typical top-down transfer of technology. In this pervasive paradigm, technology is developed in the controlled environment of universities and research stations, passed on to agricultural advisors and then to farmers, who consume and apply it ([18]: 67). Technology is perceived as a commodity delivered to farmers,

\footnotetext{
* Correspondence: elena.pagliarino@ircres.cnr.it

${ }^{1}$ Research Institute on Sustainable Economic Growth (Cnr-Ircres), Italian

National Research Council, Moncalieri (Turin), Italy

Full list of author information is available at the end of the article
}

who have little control over its development and management [22]. The transferred technologies are uniform, standardized, and mass-produced to work almost everywhere. Standardization is applied not only to physical technologies, such as seeds, pesticides, and machinery, but also to procedures and their sequencing, with the aim of routinizing the activities of farmers, thus promoting predictable and manageable changes in rural areas ([18]: 71). Some feedback is provided by the extension agents, who turn the problems of the farmers into researchable questions, then answered by research scientists. Nevertheless, the innovation pipeline is mainly linear and one-way [82].

This system has improved the availability and quality of food per capita, ensuring food security in many areas

\section{Springer Open}

(๑) The Author(s). 2020 Open Access This article is licensed under a Creative Commons Attribution 4.0 International License, which permits use, sharing, adaptation, distribution and reproduction in any medium or format, as long as you give appropriate credit to the original author(s) and the source, provide a link to the Creative Commons licence, and indicate if changes were made. The images or other third party material in this article are included in the article's Creative Commons licence, unless indicated otherwise in a credit line to the material. If material is not included in the article's Creative Commons licence and your intended use is not permitted by statutory regulation or exceeds the permitted use, you will need to obtain permission directly from the copyright holder. To view a copy of this licence, visit http://creativecommons.org/licenses/by/4.0/. 
of the world [72], and it has been a powerful tool for the diffusion of industrial agriculture [81].

While this traditional model is still practiced in many areas, its shortcomings have long been acknowledged. The reliance of farmers on suppliers of technologies, capital to buy such technologies and experts' knowledge to be able to use them has grown, limiting their margins of autonomy and creativity in farming decisions. They have also lost control over essential resources due to the concentration of power in the mechanical, seed, chemical, processing, and distribution industries. With the introduction of advanced techniques, such as genetic engineering, nanotechnology, precision agriculture, sensors, satellites, and robotics, innovation has become increasingly sophisticated and its development even more disconnected from farmers.

Chambers, Pretty and other practitioners of the "farmer first" discourse [16, 17, 77, 78] have highlighted the failure of this model in developing countries and resource-poor areas, which are more risk-prone and characterized by more complex and less controllable local conditions than the areas where the technologies and practices were actually developed.

The challenge of sustainability, posed first by the Report of the Club of Rome in 1972 and then by the Brundtland Report in 1987 and the Rio Declaration in 1992, started to be perceived as an issue only at the end of the last century [91], when it brought complexity to intensive agriculture, practiced in more developed countries. The issue of sustainability has brought to the fore the concepts of risk and uncertainty also in European agriculture. Risk and uncertainty are critical matters in agriculture and, therefore, their impact on both learning and practice needs to be taken into account. Dealing with environmental risks and developing innovations to address these risks require more inclusive ways of knowing and doing, as noted by Pimbert ([75]: 22), who stated that "more inclusive ways of knowing are required to bring together the partial and incomplete perspectives of different actors faced with uncertainty, diversity and change". This is the reason why the participatory research approach has been incorporated into European agricultural research, increasingly oriented toward the challenge of sustainability, albeit lagging behind other sectors (for example, ecosystem management, which started soon after the Rio Declaration and Agenda 21, in 1992).

Criticism of the mechanistic process of innovation has extended to all farming systems, while a broad consensus has emerged on the links between conventional agriculture and its top-down innovation, on the one hand, and the environmental crisis, on the other hand.

\section{The agroecological paradigm based on participation}

Agroecology has been proposed as a radical alternative to the Green Revolution [1, 2, 38, 87, 94]. It represents an innovative paradigm of agriculture in which external inputs are minimized, and great value is attached to the internal resources of the farm and the territory. A systemic ecological approach is adopted in order to understand the relations between living organisms and their environment. This fosters the processes that move the agroecosystem closer to a natural, mature, relatively stable, and self-sustaining ecosystem, able to maintain productivity without external inputs [37].

Our work does not explore the issue of agroecology seen as a social movement but focuses exclusively on agroecology as a system of knowledge and innovation. In this meaning, agroecological production relies on the farmers' direct management of resources and on their engagement in the governance of the agricultural knowledge and innovation system. Proponents of agroecology as an alternative development model argue that its potential can only be realized through participatory research and extension [16, 83, 84, 94, 96]. Cuéllar-Padilla and Calle-Collado [22] define agroecology as "the practice of science with people" and stress that participation is at the core of any single process. Agroecology implies the promotion of practices that (i) fit the local contexts in which they are implemented, (ii) foster the autonomy and skills of the communities involved (as is the case with the participatory research network discussed in our case study, whose learning and empowerment processes are presented in Section 3.2), (iii) profit from locallyproduced resources, included local opinions regarding sustainability (Ibidem).

A young male farmer of our network explains: "It is a question of development model. So, if we choose a development model that favors indistinct, undifferentiated production-a commodity, as it is called-this leads to cost increases. The progressive increase in costs combines with stagnation in terms of value generated by the production. To deal with decreasing revenues, one must increase the surface area. This model breaks up the farming community because the land is a finite good. If ten farmers work this land today but the model forces me to expand, some farms will grow but some others will inevitably disappear. This is entrepreneurial desertification in farming. Conversely, the organic agriculture model restores the intrinsic value of what it produces because it qualifies it and, mind you, it is not a matter of profiting excessively, of setting prices that consumers can't afford, the question is how to redistribute wealth along the production chain. Thanks to the organic system, I do this work and contribute to increasing the biodiversity of the local farming businesses."

Agroecological research requires local-scale and action-oriented solutions to deal with technical and ecological aspects, as well as economic and sociocultural dimensions, adopting a holistic perspective on agricultural 
management. The research approach needs to integrate scientific and empirical knowledge throughout the process, achieving the co-production of new crosscultural innovation $[15,36,73]$.

A university professor of the network explains: "In traditional agronomic research, we are limited to comparing fertilizers and antiparasitic agents. We decontextualize, we only look at parcels, we compare in increasing doses, we add a witness, we add replications, we use well-documented and refined statistics, we publish, and then we entrust the best technique to the extension service. The best result obtained on the parcel must necessarily also be the best result on the farm. In case of failure, we put the blame on the farmer. This is the game. Impact is not assessed, indirect effects are not considered, especially on a territorial scale. But wasn't agronomy born along with agriculture? Agronomy is life, creativity, the daily toil of those who work the land, it is not exclusively science. The real challenge lies in complexity. But all the actors have to be involved. It might seem like a longer path, but it is actually much shorter. It is the theory of interconnections, of evolution not based on competition but rather on cooperation."

A male farmer says: "Farmers are researchers by nature, but with a great limitation: they don't bother taking notes. They are not interested in writing, so they don't bother publishing the discoveries coming from their ability to adapt during agronomy activities. In the network, instead, we had to do this. We had to take notes and then discuss them with the others, even the professors, on an equal footing."

The European Commission has explicitly encouraged the transition to sustainable farming through interactive innovation and multi-actor approaches since 2012 [28], when the European Innovation Partnership for Agricultural Productivity and Sustainability (EIP-AGRI) and its Operational Groups were launched within the Common Agricultural Policy (CAP). Multi-actor projects and bottom-up thematic networks were also designed within the Horizon 2020 research and development (R\&D) framework program. The common principle was to bring together innovation actors: farmers, advisers, researchers, businesses, NGOs, and others. The collaboration among them was supposed to make the best use of complementary types of knowledge, so as to achieve the co-creation and diffusion of solutions and opportunities that would be readily implementable in practice.

In Italy, the Ministry of Agricultural Policies [62] expressed its intention to support participatory and multi-actor projects in Action 10 of the National Strategic Plan for the Development of the Organic System, emphasising the importance of knowledge sharing, coresearch and co-innovation through the involvement of various stakeholders, starting from the initial phases of research. In the call for $R \& D$ projects in organic agriculture at the end of 2018, these goals were actively pursued by requiring researchers who wished to receive financial support to include at least one farmer among their research partners and by rewarding those researchers who involved more than one farmer (Ministerial Decree no. 67374/2018).

Participatory networks have multiplied in recent years, activated as part of projects, on the basis of public cofinancing. Their diffusion is strengthened by the supporting environment, that is, by the facilitation, coordination, and training processes implemented [34]. Yet, facilitating dialogue between researchers and farmers is still a priority, which will be pursued in European agricultural policy after 2020 [26].

Mansuri and Rao [55] warn that "induced" participation-that is, participation promoted through bureaucratically managed research and development interventions-requires a fundamentally different approach, one that is long-term, context sensitive, and committed to developing a culture of learning by doing. This is why it is particularly interesting to study the experience of a spontaneous, self-directed, and fairly informal, yet highly functional network that seems to be a unique case in the Italian agricultural sector.

\section{What is true participation?}

The term "participatory research" is used to refer to various approaches and methods, and it encompasses different types of participation. A systematic review of thirty-five experiences of participatory processes, with the involvement of farmers, concluded that farmers are too often considered a mere source of information to be used by researchers rather than active participants in the management and transformation of rural areas [57].

As for participatory methods, many authors stress the importance of research mechanisms and designs to bring together scientific and practical knowledge [22, 35, 50, $56,65,99]$. Successful participatory research, it is argued, can be achieved through a structured dialogue in which the dialectical process is encouraged by regular meetings, joint reflection, and the collective development of findings and conclusions. Nevertheless, the review by Menconi et al. [57] shows that there is no preferred scheme: every initiative has its own methods and practices and is tailor-made on the researchers' preferences, resources, context, and project. However, simplicity of approach seems to be the best quality of any participatory activity (Ibidem).

As for the attitude and behavior of researchers regarding participation, the literature indicates a widespread lack of awareness, interest, time, incentives, and recognition by the current research system (e.g., $[13,25,70]$ ). Agricultural scientists have been put under growing 
pressure to undertake participatory research, but they do not have sufficient practice, skills, and competencies (Ibidem). Several authors have suggested blending various forms and intensities of stakeholders' participation with formal agricultural research (e.g., [52]), "uniting science and participation" [76], into "compromised participation" [12], making things even more difficult in terms of designing, implementing, and monitoring participatory research.

Finally, in addition to the discussion around what participation is, some authors have questioned its very value, raising the issues of inclusion, power, and governance of participation $[20,43,44,55,63]$.

Despite continuous attention paid to the topic, there is no consensus as to what participation means, how widespread it is, whether it is a sufficient goal in sustainable agriculture, and the extent to which it is actually inclusive.

Here, the experience of an Italian network for participatory research in agroecological rice production is presented with the aim to contribute to such ongoing debate. This paper focuses on the role of participatory research in the transition to sustainable agriculture, trying to shed light on if and why it is needed and what makes for good participation.

\section{Study context: the difficult conversion to organic farming of the rice district in Northern Italy}

Italy is the leading European producer of rice [31]. The crop is grown mainly in Northern Italy, mostly in the regions of Piedmont and Lombardy, where a rich, wellorganized, and interconnected district comprises farms, processing and distribution businesses, research centers and extension services, and suppliers of chemicals, seeds, and machinery [14].

The cultivation is typically intensive monoculture, without crop rotation and with heavy chemical inputs, such as fertilizers and pesticides. The impact of rice growing on the environment tends to be considered very high, especially in terms of quality of soil and surface and ground water, with risks to human health posed by drinking contaminated water [45]. The transition to organic rice farming is perceived as a solution to ensure environmental protection, economic sustainability of the farms, consumer safety, and as a measure to mitigate climate change [41, 80].

In Italy, organic farming is regarded as the most advanced and efficient way to develop an agroecological approach [68], and the discipline of agroecology finds concrete application in organic production, regardless of whether it is certified and remunerated on the market [98]. Hence, in the remainder of this study, the concepts of agroecology and organic farming will be used interchangeably.
The principles and approaches that should be adopted to manage organic farming systems are shown in European Commission (EC) Regulation 848/2018 (art. 6 and Annex II) [29]: limiting the use of non-renewable resources and external inputs, prohibiting the use of any product for weeding purposes, also of natural origin, and minimizing the use of organic fertilizers and pesticides, through measures to enhance soil life and its natural fertility (i.e., nourishing plants primarily through the soil ecosystem) and to prevent damage by pests and weeds, choosing appropriate resistant genotypes and crop rotation, and mechanical or physical methods. Therefore, the principles and approaches underlying organic agriculture are in line with the agroecological view of farming systems, although agroecology involves a wider approach, not limited to agronomic aspects, that overcomes any labels and certification systems. Agroecology aims not only to realize low-input farming systems, based on the exploitation of natural processes, but it also focuses on social-economical aspects, such as those related to human value, knowledge sharing, and equality in power distribution among the actors of the food supply chain. It is also true that, besides their principles, the regulations for organic agriculture allow the use of external products (EC Regulation 889/2008 [27]), which should be useful during the first period of transition to achieve a balance within the agroecosystem. However, in the real life of farms, this is often interpreted in a misleading way, and organic farming could follow the "input substitution approach" by replacing inputs permitted in conventional farming with others permitted in organic farming, which are not always very eco-friendly [51, 60, 61 , without changing the underlying crop management approach.

Nevertheless, in our case study, organic agriculture is the basis upon which agroecological systems are generated. The organic rice farmers involved in the network are also agroecological farmers. They follow agroecological principles in relation to both (i) agronomic aspects (i.e., soil fertilization based on leguminous species and crop rotation, plant protection based on resistant genotypes, and the management of field flooding, innovative strategies for weeding without herbicides, as explained in [69]) and (ii) social aspects (i.e., group experience of knowledge sharing and mutual learning).

With the elimination of chemicals, the production of rice must be pursued through a complex process of varieties selection, crop rotation, and agronomic techniques to enhance soil and water resources and control weeds and pathogens, while also respecting the specificities of the territory. This work requires sophisticated knowhow, experience, and skills that the Italian rice growers have long lost because they have been completely dependent on technology suppliers. The traditional 
research and advisory system is committed to ecological intensification but, due to the lack of specific funding dedicated to organic production, it has carried out few experiments on organic rice farming, mainly at the research station level [85]. The high costs of the innovative technologies developed, (e.g., mulch films and transplanting techniques, and the extreme variability of cropping systems)-depending on pedo-climatic conditions, field characteristics, and the business organization of farms-have prevented the dissemination of innovations beyond few farms. The spread of organic methods has taken place rather slowly, and organic rice production has remained niche, pursued only by a handful of pioneer farmers who, in the absence of prior knowledge, test innovative practices with a self-help and trial-and-error approach, as in Padel [71]. Organic rice cultivation was first adopted by farmers whose approach was seen as an "alternative" by the local agricultural community, i.e., biodynamic, macrobiotic, radical farmers motivated by strong environmental commitment, especially women. These farmers were initially treated with skepticism by their colleagues (as reported by [69]), sometimes even with suspicion and derision. However, their innovations were then taken up by a few pioneer farmers whose opinions are influential within the rice community, so that skepticism has now decreased, but it has not disappeared completely. This information derives from personal experiences reported by the farmers of the network. A female farmer of the network, for instance, explains that: "When the locals saw me do this work [Authors' Note: manual work to avoid the use of herbicides], under the sun, with mosquitos all around... they thought me odd, they said: 'that one has no brain'. That was another problem I had to deal with, being seen as a bit of an outsider. (...) It was very difficult. I struggled for many years. (...) I was heavily criticized because they saw that my business was earning much less than conventional farms - at the time, conventional farms were making good money-but I didn't want to maximize profit, I wanted to maximize my personal expectations..."

In this context of difficult transition to organic farming, the multi-actor agroecological network analyzed here is carrying out participatory research and innovation to enhance organic methods. Exploring the values, motivations, processes, and relations of this Italian agroecological rice network is useful to understand if and how experiences of participatory research can change the trajectory of development in areas of intensive agriculture.

Our research explored the role and mechanisms of a participatory research network for the conversion to organic agriculture. We identified the following research goals:

- To investigate learning processes and enabling environments;
- To identify limits and opportunities of participatory research networks.

The questions that guided this study include:

- Why did the farmers, researchers, and other actors join the participatory research network?

- What and how do they learn within the participatory network?

- Which are the limits and opportunities for the future of the network?

\section{Methodology}

This article draws on fieldwork investigating the partnership created by a group of farmers, scientists, government officials, and business managers in Northern Italy, between Lombardy and Piedmont, to research agroecological rice farming.

We integrate case study research and grounded theory, as in Andrade [4], choosing an interpretive approach $[33,42,79,90]$. We use qualitative methods, such as indepth interviews and participant observations, constantly acknowledging the pedagogical model provided by Tracy [92] for quality issues. Twenty in-depth interviews were conducted, from January to November 2018, with the members of the network, using a biographical approach $[66,89]$. The interviews started by asking the respondents to tell their stories. They were invited to reflect on the origin and evolution of their professional experience, the moments of change and the time when they joined the network. They were also asked to say why they decided to participate in the network and to evaluate the consequences on their work and their expectations for the future. Spontaneous discussion, listening, and empathy were privileged throughout the process. The interviews were noted down, audio and video recorded with the interviewees' permission, and later transcribed.

The functioning of the network and the relations among its members were directly observed during the partnership's meetings, from September 2017 to December 2018. It was also possible to be involved in the informal exchange of messages among the participants via social networks and email.

Midgley [59] says that supporting evidence is often based on single case studies of intervention, and Meyer [54] points out the need to consider what is unique in each intervention. Our case study describes a small network of 28 people featuring farmers, researchers, and other actors. Other European networks have the same small number of participants, around thirty [40]. Therefore, the number of in-depth interviews (20), covering $70 \%$ of the network participants and integrated with the results of the observations made directly by the 
researchers during the network meetings over 16 months, appears reasonable and justifiable.

Objectives, methodologies, results, drivers of change, values, and visions were analyzed using grounded theory to develop an understanding of the processes of participation, assumption of responsibility, learning, and innovation. Grounded theory, in its latest evolution (e.g., $[19,21])$, is an interpretive method used to systematically analyze texts, such as interview transcripts and observation notes, in order to build theory concepts. This is done by reading the texts with specific questions in mind, extracting themes, and coding passages with keywords and quotes.

The narrative approach is used extensively in participatory social science, i.e., education, psychology, youth and childhood studies, geography, and land management science (for example, [86]). We found few applications in rural studies. In Phillips and Dickie [74], the narrative approach has been adopted to explore the rural future associated with climate change. Boxelaar et al. [10] explored how narrative approach can facilitate change in land management, demonstrating that this approach highlighted some of the ambiguities that existed within the project, but it did very little to change the course of the project. Kajamaa [47] shows that the narrative approach is appropriate to enrich participatory research when used in a complementary way to other ethnographic methods, such as in our case.

With the aim to explore which elements of the participatory research network support the transition to organic farming, the material was organized to fit into these categories:

- Objectives, structure and functioning of the network;

- Processes in the network;

- Values shared;

- Relations, power, and inclusion.

\section{Results and discussion}

\section{The Riso Bio Vero network}

The Riso Bio Vero (RBV) network brings together several organic rice farmers from the heart of the Italian rice district (provinces of Pavia, Vercelli, and Novara), as well as from outside this area. Scientists, public officials, and the managers of a company distributing organic products have also joined the network. The agricultural component of the group is not very representative of Italian farmers. According to the latest census of agriculture [46], in Italy, $30.7 \%$ of farmers are women, $2.5 \%$ are under $40,6.2 \%$ are graduates, and only $0.8 \%$ have a degree in agriculture. In Europe [30], the first three figures are respectively: $28 \%, 11 \%$, and $7.5 \%$. In the RBV network, instead, women, young people, and graduates are well represented (respectively, 7 out of 17,3 out of 17, and all) (Table 1).

The most recent data on the structure of European agriculture [30] suggest that, on average, $28 \%$ of farms across the EU are managed by women, with considerable differences among countries. In Lithuania and Latvia, nearly half of all the farms are managed by women; by contrast, in Finland, Malta, Germany, Denmark, and the Netherlands, the proportion of female farm managers does not exceed $10 \%$. Many studies demonstrate that participatory and agroecological approaches can be gender-sensitive, i.e., able to address the issues of gender inequality and inclusion (see for example, [39, 67]).

Only $11 \%$ of all farm holdings in the European Union (EU) are run by farmers under $40(6.9 \%$ by farmers younger than 35 and just $4.9 \%$ by women under the age of 35) [30], and persuading more young people to begin farming is a major challenge [5]. The EU is encouraging young people to take up farming with start-up grants, income support, and benefits, such as additional training (Ibidem). Flament and Macias [32] highlight that a growing number of urban youths, often with a university degree, are deciding to become farmers. Described as "new peasants", many of them choose agroecology as an alternative way to enter the food system, promoting both social and environmental sustainability. The idea of young farmers being "innovative" and turning away from traditionally intensive industrial farming models was already promoted by de Rooij in 2004 [23].

On average, only $7.5 \%$ of the current generation of European farmers have received full agricultural training, and $73.5 \%$ only have practical agricultural skills, coming from professional experience. Among farm managers, educational attainment is lower among women than

Table 1 Network members by category, gender and age

\begin{tabular}{llll}
\hline & Network members* & Women* $^{*}$ & ${\text { Under } 40 \text { years of age* }^{*}}^{\text {Farmers }}$ \\
Scientists & $17(13)$ & $7(4)$ & $4(4)$ \\
Business managers & $6(3)$ & $4(2)$ & $2(1)$ \\
Public officials & $2(2)$ & & 1 \\
Total & $3(2)$ & $2(1)$ & 9 \\
\hline
\end{tabular}

*Interviewees in brackets 
men (5\% versus $10 \%$ for full agricultural training and $79 \%$ versus $68 \%$ for only practical training) [30].

The RBV network was established in 2016 thanks to the coming together of a group of people who, despite knowing one another, until then had only occasionally collaborated. The intensification of their relations was linked to the opportunity, offered by the University of Milan, to organize the second international conference on Organic Rice Production (ORP 2) in Milan, on the occasion of EXPO 2015, the Universal Exposition hosted by Italy and focusing on food and agriculture. The conference was very successful; teamwork was stimulating; and the goal of continuing to work more steadily together was reinforced. The people who took part in the organization of the conference felt that they had a common vision of their work and that together they could defend and enhance their activities, even against the harsh attacks suffered by the sector. At the end of 2014, in fact, a television reportage (Report on the national TV channel Rai3) had revealed the phenomenon of "falsi bio" (false organic producers), triggering a crisis that affected the entire rice industry, both organic and conventional, and still persists. Attacks on the image of organic rice farming played a crucial role in the decision to establish the group called "Riso Bio Vero" (True Organic Rice) to affirm the integrity of a portion of organic rice growers and their firm condemnation of fake organic producers.

A young farmer of the network explains the "false bio" phenomenon in Italy by saying:

"We are $100 \%$ organic, which is a very important choice to give the business credibility. In 2014, I was among those who fought the hardest against the issue of fake organic rice. When I started the conversion, I saw that some of my competitors basically produced in the traditional way, but then all their papers were in order to obtain the certification. This is damaging to honest organic producers, consumers, as well as to conventional producers, who choose to follow the rules and don't give in to the golden opportunity of making easy money. Unfair competition swallows up other businesses. Both conventional and organic farmers are wiped out by those who do not comply with the rules. In 2014, together with other farmers, I decided to expose this unacceptable situation. We did it, for example, by collaborating with Report (there were many other initiatives, but Report achieved the greatest visibility). We were involved in writing the episode of the program about this issue, which became a sort of turning point in Italy's organic rice production and, to an extent, in the organic production of other sectors too. Before that, there were thousands of hectares of organic rice cultivation that were actually farmed in the conventional way. There was no crop rotation, the embankments had no vegetation-and
I have never seen land remaining bare without undergoing treatment. Since Report, the history of organic farming has changed. From then on, there has been much more attention from the institutions, from politics, born of our denunciation, of our raising awareness and rebelling, of our will to redeem the sector, especially on the part of young farmers who can't tolerate living in such a... how can I put this... such an unfair world."

The group's original core included ten organic rice farmers (four from Lombardy, five from Piedmont and one from Tuscany), a professor from the University of Milan, an official from the Lombardy Region, and a representative of a company distributing organic products. Afterwards, a retired official of the Piedmont Region and a professor from the University of Pavia also joined. Both academics made available to the network their research groups, made up of technicians and young researchers.

Thanks to the participation of the University of Milan in the Riso-Biosystems national project (2017-2019), two scientists from two different public research institutions joined the network too. Furthermore, the research activity became a specific work package of the project. Although it would be very interesting to analyze the relationships between the RBV network and the rest of the partnership and the level of integration achieved, such a topic is not the subject of this study.

Subsequently, some organic rice growers became members of the network either permanently (two farmers from Piedmont) or occasionally (farmers from Veneto).

The group was founded with the aim to demonstrate that organic rice can be produced in a serious way, without circumventing the limits imposed by European regulations, which forbid the use of chemicals. The group of pioneer farmers have come together to promote their common interests, i.e., demonstrating the methods and best practices at the basis of professional organic rice production. They are all officially certified organic farmers. However, their views go beyond any labels, because they believe in the agroecological approach, which regards the farm as a living system that interacts with the environment and the socio-political structure of the territory. For these reasons, they do not consider organic farming a mere sustainable alternative to conventional farming and aim to avoid products that are permitted by organic farming regulations but not environmentally friendly. They have also focused on exposing the strategies of fake organic rice producers, which circumvent the limits imposed by the European regulations forbidding the use of chemicals. Indeed, the rice sector is particular prone to fraud since, differently from other productions, organic and conventional farms share the same irrigation system, based on a network of 
watercourses and channels that cross the valley of the river Po. Therefore, the auditing authorities cannot deem traces of banned chemicals in rice plants to be objective proof of forbidden treatments, since it is impossible to exclude accidental contamination through the sharing of irrigation water. Furthermore, the lack of chemical residues on the rice grain, despite repeated spraying of the plant, which is a good point for consumers, prevents the distinction between the production obtained with the organic method and that obtained with the conventional method, making organic cultivation susceptible to fraud.

Around this goal, the group began to collaborate by sharing previous knowledge and experiences. The partnership gathered latent discontent toward conventional rice cultivation and bitter frustration toward false organic farmers, channeling them into a participatory research system that would allow experimentation and innovation in agroecological rice cultivation.

\section{Network's role, activities, and structure}

Participation in the group allows its members to share know-how and improve individual techniques, quickly adopting and adapting innovations successfully tested by others and, above all, starting a new research process "from below". The exchange of individual experiences is very important for the site specificity of organic practices. Due to extreme variability in microclimate and soil conditions, as well as in farmers' resources, capacities and organization, a good technique for one farm may not be feasible or suitable for another. Testing different techniques at the same time within a single context, as seen in parcel experimentation both at the farm and research station level, does not provide useful results in organic farming $[8,48,88]$. Vice versa, the application of the same technique to many different farms allows the growers to produce new insights and learn from one another. The first approach assumes a certain level of uniformity of cropping conditions across different farms. It transfers the results obtained from experimental trials, implying convergence of innovation through a standardized pattern of techniques, valid for different places and different times (the "funnel" scheme). Unfortunately, organic fields are unpredictably diverse, due to the reduction of external inputs that minimize possible sources of variability. Farmer-led trials reveal the constraints and benefits of different techniques by applying them to a wide range of field conditions and farm contexts and then selecting and adapting those that best respond to the specific characteristics of each farm ("folding fan" scheme). Bell and Bellon [6] explain the difference between the two approaches in terms of universalization versus generalization. The active involvement of the farmers in the research process makes it possible to experiment and adapt the same techniques to different farms, to achieve the quick and efficient generalization of best practices. Because of the extreme variability of environmental conditions among organic farms, even those where the same species are grown, the rapid dissemination of innovative results would not be feasible if the farmers were not involved-that is, if it were not supported by those who spend most of their time in the fields, carefully observing nature and its interactions with their own work, supervising the experiments and verifying their results year after year.

"Results come from individual experience, but experience comes from the exchanges among the farmers, who experiment with different techniques, each on their own land, each with their entrepreneurial approach. The mixing, discussion and reflection with the researchers and officials brings about improvements in the sector. Everyone has given and received much-this is the true strength of a network. We have become a network because we have done a lot of sharing, guided by mutual trust." (Female farmer)

The activity of the network has allowed its members to improve existing agronomic techniques, increase and stabilize yields, and make actual discoveries, such as those regarding the allelopathic function of some species used as cover crop.

The research process is complemented by mutual assistance in the choice of machinery and suppliers, as well as in the management of the business, marketing strategies, information on regulations, and funding opportunities.

At first, discussion and collaboration among the members of the network concentrated on agronomic practices, the performance and constraints of little known agro-techniques, and issues of business administration and marketing. Then, the focus widened to include questions not strictly related to farming, e.g., measures to improve the transparency and integrity of the supply chain (critical issues and opportunities regarding both the improvement of the traditional organic certification system and alternative participative certification systems), practices to enhance plant biodiversity in the paddy fields, etc.

The governance of the network is very simple. A rice grower acts as leader of the farmer members, while a research fellow from the University of Milan serves as a bridge to the academic component and animates the entire network by taking care of overall communication. The group meets periodically, about once a month, preferably at the home of the farmers' leader. The meetings last a whole day and include a shared lunch, for which everyone brings something that they have cooked. Regular attendance is supported by sharing meals and by common participation in other activities (e.g., training visits, trade fairs). The fact that all the participants invest 
a great deal of time in the network meetings and activities is not seen as a limit, but as a strength of the network.

The agenda of the meetings is set and shared by email. The researchers and farmers' leader facilitate the discussion, which flows quite spontaneously, and use a projector to present data, results and videos, but no particular participatory method or approach is deliberately used. Sometimes, visits to one or more farms follow the discussion and help to verify the progress of the experiments undertaken directly in the field.

Outreach initiatives are carried out together with the research activity, including scientific publications authored by all the members of the network, seminars and conferences (i.e., ORP3 in Brazil in 2018 and a national conference open to all the actors of the supply chain, including the media, in Milan in 2019). The network is also preparing a manual for the identification of weeds in the paddy fields, a summary document on yields in organic rice cultivation and self-checking guidelines for the certification system.

\section{Research process}

The research process is managed through four cyclically repeating phases:

1. A phase of discussion concerning the issues detected in daily practice and possible experiments to investigate them.

2. A phase of experimentation conducted by the rice growers on their own farms but monitored by the farmers' leader and the research fellow, who periodically visit the farmers and assist them with their technical needs, both directly in the fields and from a distance via social networks and email. At times, neighboring farmers also take part in the visits, to see the fields and give suggestions.

3. A collective phase of gathering, sharing, analyzing, and interpreting the results.

4. A phase of adoption of innovations at the farm level and identification of further critical issues.

Without knowing it, the growers are using the cycle learning process proposed by Kolb in his theory on experiential learning [49], in which concrete experience, reflective observation, abstract conceptualization, and active experimentation follow one another. Such an approach does not involve specific planning or the use of facilitating tools; rather, it centers around a reflexive, flexible, and iterative process. The action-reflection cycle helps establish a body of knowledge that is constructed and refined by the participants and represents a synthesis of the different skills brought to the partnership. A good example of this process is the research activity on plant biodiversity. During a conference, a farmer came into contact with some academics from the University of Pavia who were talking about a typical indigenous species found in the paddy fields (Marsilea quadrifolia L.), which had been declared endangered due to massive herbicide use [11]. The farmer recognized the plant from having seen it in her fields and invited the incredulous scientists to visit her farm. The discovery triggered a research project, carried out on the land of all the farmers in the network and in the university lab, to verify the relationship between agronomic practices and plant biodiversity and enhance the ecological function of the paddy fields. It also offered the opportunity to design the brand "Marsilea rice", to be used on the market to strengthen the identity of the group in opposition to false organic farmers. This example clearly shows how flexible the network is in its activities and scope, effectively combining a wide range of disciplines.

The members of the network are all at the same level and participate in the research and innovation process without a hierarchical approach. The academics provide their knowledge and stimulate the adoption of scientific procedures, but they are open to new forms of learning from cross-cultural exchange. They emphasize that their involvement in the network is driven by genuine interest in participatory research, curiosity about its functioning and fun and excitement in experimenting alternative forms of doing research. They admit that this research approach is not successful in terms of publications.

"Now I want to test this new approach, understand if it works, where it doesn't work, why it works, with the clear and critical thinking of a researcher, without taking for granted that it will be a successful process. For instance, in terms of publications, it isn't, but it is undoubtedly more interesting, fun, and exciting." (Professor, male)

The scientists have backgrounds in agronomy, natural sciences, agricultural economy, and rural sociology, but they lack specific skills in participatory methodology. They share a commitment to participatory research that prioritizes respect, trust, and openness to experience, and their attitude is fundamental to ensure good relationships with the farmers and the other actors in the network. The researchers take the farmers' skills very seriously to prioritize research aims and develop and validate agronomic practices. This trust is perceived by the farmers and reciprocated. Indeed, regular and direct contact between the researchers and the farmers allows them to strengthen the feeling of mutual trust that they have built.

The fact that a company distributing organic products has been present since the establishment of the network has meant that many of the farmers involved have 
signed a supply contract with this company. The agreement requires compliance with a set of strict cultivation guidelines deemed to be even more stringent than that required by the European organic certification regulations.

A female farmer explains: "It is an unbelievably strict contract. When you sign it, you accept being under constant monitoring, with two checks, one during the growth phase, when a rice sample is taken and analyzed, and another before the harvest-two multi-residual analyses-and then constant technical inspections. There is also a sort of protocol involving green manure or harrowing, so using cover crops or rotary tillers, but no support whatsoever."

According to the producers, this seriousness is a guarantee for their image and is well remunerated by their buyers. So far, this economic relationship among many members of the network has not been considered an obstacle to the group's research and innovation goals.

The network's research activities have been funded through public and private tenders (e.g., bank foundations), and some members have supported them with their own funds. Although this is an example of bottom-up research funding, the extemporaneous and unorganized nature of such support prevents any assessment of this aspect.

Furthermore, the members have not yet taken into consideration issues of research ethics, such as confidentiality, property of innovations, and conflicts of interest.

\section{Shared values}

When the members of the network describe the values that they share, they mention a wide variety of topics, such as environmental commitment, responsible business ethics, economic rationality, aesthetics, and enhanced satisfaction in doing their job. Some common principles recur in the narratives collected through the interviews:

- The members of the group are engaged in organic rice cultivation because they pursue not only economic profit, but also the protection of the environment in which they work and live, for themselves and for others.

"The radical decision of going organic, which I made a few years ago, was motivated, above all, by the situation of the market, which no longer offered any guarantee of profit or sustainability from any point of view. In my opinion, organic farming went instead in the direction of sustainability and business growth oriented toward the future. It means meeting the needs of aware consumers, producing a series of positive externalities besides the mere production of foodstuff. To me, being an organic rice producer today means being a business that yields a better type of food in many regards, provides a healthy environment, and is attentive to resources, which are not my private resources but common goods for the whole community, such as water and soil. Making this choice provides positive answers to all of these issues. This is what doing organic farming means." (Young male farmer)

- They believe that farmers must take responsibility for the environmental impact of agriculture.

- They honor this commitment with courage.

- They include ethics among the most important values of their activity.

"Climate change has forced us to face our responsibilities. Science is not neutral; it is not aseptic. Passion, ethics, values, ideals, and vision must be part of research. In organic farming, this is a viable path. It is not just a utopia; it is technically feasible too." (Professor, male)

- They believe that in organic farming, they can express their creativity, professionalism, and values, which were frustrated in conventional agriculture.

"Doing organic farming means doing varied and creative work. This is what organic farming requires. The seasons change every year and there is no fixed date for sowing, no fixed protocol, it changes from land to land. So, you need a lot of focus and a creative mind. Agriculture of this sort relies on everyone's collaboration, intelligence and creativity. And everyone is important." (Female farmer)

"The biggest difference between conventional farmers and organic farmers is that organic farmers feel peace of mind, they know that they're doing the right thing. This is the underlying reason, they know that they are working at their best, that their cultivation methods are superior in quality, without compromises, and that there is no one to tell them what they should do, to give them chemicals. They know that they are working healthy fields, not sick fields constantly in need of chemicals for this and that." (Female farmer)

- Basing their work largely on their own abilities and resources, they feel more responsible, autonomous and free of constraints than when they used conventional methods and were highly dependent on external inputs.

"I decided to work the land with my own hands because I have always liked nature. As a child, I went to the countryside and I spent entire days observing the colors, the light, the shapes of nature. Being able to do a 
job that would bring me back to a place that was natural to me was the right choice. Obviously, it is not all bucolic and effortless. You are faced with all the problems of a much more difficult type of agriculture that puts you in direct correlation with nature, makes you use your brain. No technician comes along to tell you what to do. There are no technicians in organic rice farming. It's all up to us. So, this also makes you more perceptive." (Female farmer)

- They believe that organic farming is a means of reducing costs and earning the right income for a decent life. When they practiced conventional cropping, most of their revenues were used to pay consultants and suppliers, and the margins to live with dignity were limited.

"I hope I'll have a proud future, not a meagre one, not only in economic terms, but also from the point of view of the dignity of my work, which has something to give to everyone. I want to keep doing this with my head held high and I want those who will come after me to be able to do the same, with the same pride, the same determination, the same will to do it well." (Young male farmer)

- They find satisfaction working in contact with the land and aesthetic pleasure in the observation of nature: They believe that organic farming is the only way to preserve the beauty of nature and live in harmony with it.

"This is the land I got from my ancestors, my father and grandfather. I am proud to own it and I have always felt the responsibility of owning this land. The choice of going organic developed over many years, out of the awareness that we belong to nature and, as nature's children, we are called upon to practice farming that respects nature, that loves it." (Female farmer)

- Their mission is to prove that organic rice cultivation can be carried out seriously and transparently.

They express their opinions and values with a very high level of emotional engagement. "Years ago, if I had had to imagine what my future business and my profession would be like, I would have never imagined, never even dreamed, that I could reach such a high level of satisfaction, creation of common work, collaboration with other farmers, with universities, with the Ministry. Not in my wildest dreams. I am so very happy." (Female farmer)
In the network, they have created a physical, epistemic, and emotional space in which they meet and engage in shared knowledge production, free of power relations.

A young male farmer says: "During our meetings, it happens that at the start I have an opinion and, by the end, I have changed my mind completely. For someone like me, that is pretty strange. It's not easy for me to admit that my ideas were not so good after all. This is what happens in our group. The discussions and sharing all together, each with their own opinions, allow us to come up with new, better ideas. This is possible since all points of view are equally important and no one is judged because of what they say."

A female farmer adds: "We didn't keep anything to ourselves, if one of us found out how to do something, they would tell the others: look, this is how you can do it. (...) I don't necessarily say the right things. Someone else might see things differently and have the right intuition for that situation. Then, when all's said and done, I will also agree that what that person said was right..."

Speaking about the professor who is a member of the network, another female farmer says: "He was very smart, he said: I have nothing to teach you from a technical point of view. It is you who should teach me. You know all the methods. We got on well with him, because he's an intelligent person, he gets things right away. That's how this participated research came about. $\mathrm{He}$ had twelve serious businesses to collaborate with."

In such a space, practices and emotions are both valued and legitimated. Many of the members of the group state that they have become friends and that this has allowed them to overcome the sense of loneliness widespread among organic rice farmers, which continues to be one of the main motivations for participating in the activities of the group.

A female farmer says: "We've also become friends, because we have met very often, we have shared many things. We spend whole days together, so we socialize, we share our problems, the nice moments, our emotions too, like the storks on the electricity poles, the frogs hopping all around, some strange bird we saw for the first time, the selfies... (...) In my opinion, this is another step in participatory research. It counts too. It has been a big help because we don't feel lonely... Otherwise, you know, they tell you you're odd, you're a fool, why should you bother when you can just spray something, since no one checks anyway... so you start feeling isolated, very much so. I think it is greatly appreciated and it is the right way forward."

Emotions emerge as an important factor in the innovative learning process of the network, as described in Lund and Chemi [53] and Bellocchi et al. [7].

The fact that agronomic science and agricultural practice are very close has fostered their mutual 
understanding. They speak a common language, but what has truly brought them together is the sharing of a common mission, vision, and responsibility.

The peculiarity of the RBV network is that it is made up of people that have different degrees of authority and knowledge, and yet come together. Power differences (which inevitably exist between farmers, government officials, academics, etc.) are overcome and, although the more charismatic people act as leaders, the network is not hierarchical, since each member has put a collective goal (i.e., the research objectives) before their professional aims (i.e., profit, publications, etc.). This entails more relaxed interactions, as the spirit of collaboration seems to reduce the dynamics of power normally expressed in a competitive environment.

A young female researcher says: "I used to work in another university and I was very frustrated. The way of doing research was oriented toward competition and I didn't like that, but I saw no alternative. That was how the system worked and I was a newcomer, I counted for nothing. Then, one day, I was at a congress, sitting next to the professor who was my thesis advisor. A colleague from our group was presenting some results, which came largely from my field work. I had worked so hard for my $\mathrm{PhD}$. And this colleague was showing an article, bearing the names of all the people in the workgroup, except mine. I looked again, I thought I had to be wrong. I turned toward my professor and he said: 'See how nasty we can be?'. I wanted to cry. But that moment made me understand that I had to change. I came here and I started working on this project, together with the farmers. I might never have a university career, but this work gives me satisfaction. I spend time in the fields with the farmers and I learn a great deal from them. We have published in international journals and we have put the names of all the farmers involved, specifically to acknowledge their contribution."

\section{Future of the network}

The network defines itself as open and inclusive, but it has not established rules for the admission of new members, and applications to join made by other producers are assessed very carefully by the member farmers. The key requirement is to adhere to the principles of seriousness that characterize the network and, until now, this has been assessed through direct knowledge of the rice growers and their fields. During the process of inclusion of new farmers, the importance of relationships based on trust means that applicants are accepted only if they are considered "true organic", beyond any official certification.

The network also features some public officials belonging to the institutions tasked with shaping policies for the transformation of rural areas, but so far, no initiative has been launched to stimulate a formal dialogue with these institutions.

The farmers are very directly involved in the network, appreciate the research activity and equal relationship with the researchers, and intend to formalize it in the near future. For their part, the researchers find this kind of work promising and engaging. The environmental outcomes of supporting a group of pioneering farmers involved in the difficult conversion to organic production justify the commitment of public personnel (researchers and officials), at least for now. In the future, the role of both researchers and officials will need to be redefined to avoid criticism for supporting a private group. The scaling-up of the research focus from mainly agronomic interests to the pursuit of sustainable development goals may also eventually motivate public participation. A workshop to understand if and how to incorporate the Sustainable Development Goals of Agenda 2030 [93] into the network has been conducted, but it has not led to any concrete assumption of responsibility.

\section{Conclusions}

The RBV network is a group of diverse actors from the organic rice sector participating in collective, selfplanned, and self-developed research. Farmers, scientists, extension agents, government officials, and business managers are co-learning and co-producing knowledge and innovation. This public-private partnership is a voluntary, multi-year relationship that addresses the needs of the organic rice farmers, as well as those of the territory and the community, i.e., environmental issues and integrity of the supply chain.

An effective process of scientific and local knowledge sharing is taking place within the network. Cooperation is based on mutual trust and a common concern, i.e., how to shift from high-input cropping to organic farming, with the ultimate goal of protecting the environment and human well-being. The members' active participation is mainly due to the fact that the activities carried out originate from real needs and concrete research questions.

The network follows a loosely structured agenda that allows for the continuous inclusion of new matters related to organic rice farming. In contrast to traditional research projects, which are planned in advance and leave little room for changes in goals, activities and methods, the spontaneous nature of this group generates high variability in the issues addressed, constantly reorienting its approach toward the emerging research questions.

This is a self-building group, formed around existing social relations, but inclusive and flexible: the joining of new actors (i.e., additional farmers, researchers skilled in 
specific topics, supply chain operators, etc.) is actively pursued through dissemination activities.

The participants show a very high degree of commitment and responsibility. The most evident sign of this is the considerable amount of time dedicated to research, both on the farms and in the regular meetings. All the members of the network are equally involved in the process of (i) defining the research questions and the activities to answer such questions, (ii) managing the research activities and the network's organization, (iii) finding the resources needed for the research, inside and outside the network, and (iv) interpreting and evaluating the results. Such engagement is what makes them responsible, which is further confirmed by their strong motivation to disseminate the research results among other stakeholders outside the network.

Their involvement in the research process is transformative for the participants, who clearly admit that, by joining the network, they have changed their practices but also their ideas and beliefs. Such learning can create further transformations both in the sector and in the territory. Thanks to their intense communication work, the project findings are shared with other farmers and stakeholders and the network's perspectives are brought to the attention of the institutions tasked with decisions on the transformation of rural areas. It will be interesting to follow the evolution of this network, so as to understand if it will essentially remain a group of friends engaged in collaborative research activities or if it will be able to develop into a model of innovation for the sector and an interlocutor for public decision-makers. In order to become an actor in the scientific and political debate, the network will probably need a more organized structure and include other relevant stakeholders, such as consumers, rural dwellers, and environmental NGOs.

Home and Rump [40] analyze 17 European Learning and Innovation Networks in Sustainable Agriculture (LINSAs) as part of the EU transdisciplinary research project SOLINSA. LINSAs are defined as networks of producers, consumers, experts, NGOs, SMEs, local administrations, researchers, and/or extensionists who are mutually engaged in pursuing common goals for sustainable agriculture and rural development, cooperating, sharing resources, and co-producing new knowledge by creating the right conditions for communication. Our case fits this definition perfectly. Home and Rump (Ibi$\mathrm{dem})$ recognize a wide variety of network typologies: from local scale to national or transnational; from small, simple homogenous networks to large, complex and diverse networks with multiple actors and "networks of networks"; from incremental to radical innovation; from top-down to bottom-up origin; and with several action fields, including non-food oriented, food production oriented and consumer oriented. Their study shows that
LINSAs may emerge from small groups of farmers or may be inspired by individuals; they may develop as the formalization of an existing diffuse network or grow through a progressive process of co-opting local groups. Their size can vary from small (about 30 members), as in our case study, to about 100,000 farmers and 2,500 facilitators. Compared with the case studies presented by the two authors, our network has the following key characteristics:

- Trans-regional scale (several regions of northern Italy);

- Small dimension and simple structure;

- Heterogeneous participation in terms of gender and age, but more homogeneous participation in terms of experiences and values (e.g., all the members are oriented toward the production of organic rice) and categories involved (consumers and NGOs are not present);

- Commitment to both radical innovations (transition from conventional to organic rice) and incremental innovations;

- Spontaneous, bottom-up origin;

- Various action fields, including food production oriented, non-food oriented (environmental impact) and consumer oriented;

- Low degree of formality;

- Loose network with closed boundaries (participation in the network is voluntary, but the inclusion of new members appears to be contingent on sharing the same values, i.e., conventional farmers not willing to change are not accepted).

Participatory network experiences, especially for organic production, can be improved by considering the results of our analysis. In particular, in line with evidence from other studies [34], the importance of a supporting environment that facilitates and coordinates the learning processes is confirmed. What our case study highlights is that this environment can also be hardly structured or formalized. Indeed, it appears that the informal nature of the network is one of the key factors in its success.

As in Mukute and Lotz-Sisitka [64], collective learning happens when a group of people with different experiences and perspectives work together on the same issues and seek to jointly develop new knowledge or tools to address problems. As in Benton and Craib [9], in the learning process there is an emancipatory intent that is committed to changing unsatisfactory and oppressive realities, such as the socioeconomic and ethical crisis in the rice sector that started in 2014.

As Von Münchhausen and Häring [95] conclude, farmer-university networks function effectively if all 
their participants are considered equal partners. The findings of our research confirm the results of Home and Rump [40] who analyzed 17 networks, concluding with the identification of common factors that contribute to successful collaboration. Among these is the need to identify and build a working relationship with key partners, based on mutual trust and commitment, to strike a balance between guidance and listening, interactions and freedom, and to pursue positive and critical reflection-a fragile equilibrium that is difficult and time consuming to establish.

As in Mendez et al. [58], mutual learning takes place thanks to reciprocated trust, commitment and responsibility by all actors. These processes are favored by shared values. As a professor in our network points out, "Science is not neutral; it is not aseptic. Passion, ethics, values, ideals, and vision must be part of research."

Mutual understanding is fostered by the use of a common language, both technical and methodological. Although applied for the first time in the network, the participatory approach has been fully espoused by its members. Despite being no experts in participation techniques, the network members understand and approve the reasons for participation.

The farmers involved in the network are well educated, unlike most farmers, and this aspect may influence their ability to speak a common language, comprehended by both the researchers and the other farmers.

The conversion to organic is often seen as a matter of procedures codified by regulations for a given period of time. For farmers, however, as the case study shows, conversion does not restrict itself to these procedures, but entails transformations that transcend any legal period and definition and have to do with the learning process that occurs in the network.

Our study results contribute to the participatory research approach by showing that personal values and attitudes are crucial. These certainly originate in the professional and human paths of the people involved, but can be developed both in education and training courses and through coaching and tutoring initiatives by other farmers and researchers who have had similar positive experiences.

Agroecology is an alternative development model to the failure of the traditional top-down innovation approach. It is said to be a knowledge intensive-as opposed to input intensive-agricultural practice [3, 24]. Agroecology is also defined as the integration of scientific disciplines, agricultural practices, and social movements [97]. Hence, it requires an interdisciplinary approach to knowledge and pluralism in the ways of knowing. Participatory research, that is a transdisciplinary process, can therefore be seen as the right approach for the transition to agroecology. However, participatory processes need skillful researchers and farmers who have the ability to implement them and are willing to engage in the collaboration themselves. If we look at the matter from a sectoral perspective, the development of human capital receives little attention in the CAP. As highlighted by several recent studies, reforms are needed in this respect. A key suggestion that can be drawn from our case study is that of investing in the development of human capital and in the education of farmers and researchers in an integrated and coordinated way, so that they can develop skills in both agroecology practice and participatory research, designing new curricula in technical schools and universities and promoting the exchange of experiences between networks. A strong push toward education in farming is needed. Initial training is of national competence and agricultural education systems vary widely throughout the EU. But better integration between school and academic education and lifelong training is planned for the future through the European Social Fund and the CAP's second pillar on Rural Development [5]. The future of European Participatory Research Networks can benefit from this integration. At the same time, bringing together complementary types of knowledge in a transdisciplinary approach, they can support that integration in innovative ways.

\section{Acknowledgements \\ The authors acknowledge with gratitude the active involvement of the Riso Bio Vero network members and their willingness to tell their stories and share their thoughts. The interpretations in this article remain the authors' own.}

\section{Authors' contributions}

All authors contributed to the conception and design of the work; EP and FO devoted themselves to the acquisition, analysis, and interpretation of data; EP have drafted the work and all authors substantively revised it. The authors read and approved the final manuscript.

\section{Funding}

This study was carried out as part of the Riso-Biosystems three-year project (2017-2019), funded by the Italian Ministry of Agriculture, Food and Forestry Policies to study and promote organic rice. The funding body does not have any role in the design of the study, in the collection, analysis, and interpretation of the data and in the writing of the manuscript.

\section{Availability of data and materials}

The data supporting the findings of this study (audio and video recordings of the interviews; direct observation notes) are not publicly available, as they contain information that may compromise the privacy of those participating in the research, but are available from the corresponding author on reasonable request.

\section{Ethics approval and consent to participate}

This study was conducted in compliance with the CNR Code of Conduct of $10 / 20 / 2017$, whose observance is supervised by the Institute Director, and in compliance with the University of Milan's Code of Ethics and for Research Integrity, issued by Rectoral Decree 224/2019 of 18/01/2019. 


\section{Competing interests}

The authors declare that they have no competing interests.

\section{Author details}

'Research Institute on Sustainable Economic Growth (Cnr-Ircres), Italian National Research Council, Moncalieri (Turin), Italy. ${ }^{2}$ Department of

Environmental Science and Policy, University of Milan, Milan, Italy.

\section{Received: 9 October 2019 Accepted: 3 August 2020}

Published online: 19 August 2020

\section{References}

1. Altieri MA (1989) Agroecology: a new research and development paradigm for world agriculture. Agric Ecosystems Environ 27(1):37-46

2. Altieri MA (2002) Agroecology: the science of natural resource management for poor farmers in marginal environments. Agric Ecosystems Environ 93(1): $1-24$

3. Altieri M, Nicholls Cl (2012) Agroecology scaling up for food sovereignty and resiliency. In: Lichtfouse E (ed) Sustainable Agriculture Reviews, vol 11, pp 1-29

4. Andrade AD (2009) Interpretive research aiming at theory building: adopting and adapting the case study design. Qual Rep 14(1):42-60

5. Augère-Granier, M.L. 2017. Agricultural education and lifelong training in the EU. European Parliamentary Research Service [WWW] https://www.europarl. europa.eu/RegData/etudes/BRIE/2017/608788/EPRS_BRI(2017)608788_EN.pdf (visited on 02/06/2020).

6. Bell MM, Bellon S (2018) Generalization without universalization: towards an agroecology theory. Agroecol Sustainable Food Syst 42(6):605-611

7. Bellocchi A, Quigley C, Otrel-Cass K (2017) Exploring emotions, aesthetics and wellbeing in science education research. Springer Cultural Studies of Science Education 13

8. Bengtsson J, Ahnström J, Weibull AC (2005) The effects of organic agriculture on biodiversity and abundance: a meta-analysis. Journal of applied ecology 42(2):261-269

9. Benton T, Craib I (2001) Critical realism and the social sciences. In Benton, T. and Craib, I. (eds.) Philosophy of science. The Philosophical Foundations of Social Thought, Palgrave Macmillan, Basingstoke, pp 119-139

10. Boxelaar L, Paine M, Beilin R (2007) Change management and complexity: the case for narrative action research. The Journal of Agricultural Education and Extension 13(3):163-176

11. Bruni I, Gentili R, De Mattia F, Cortis P, Rossi G, Labra M (2013) A multi-level analysis to evaluate the extinction risk of and conservation strategy for the aquatic fern Marsilea quadrifolia L. in Europe. Aquatic botany 111:35-42

12. Buhler W, Morse S, Arthur E, Bolton S, Mann J (2002) Science, agriculture, and research: a compromised participation? Earthscan, London

13. Caister K, Green M, Worth S (2011) Learning how to be participatory: an emergent research agenda. Action Res 10(1):22-39

14. Caraveli H (2000) A comparative analysis on intensification and extensification in Mediterranean agriculture: dilemmas for LFAs policy. J Rural Stud 16(2):231-242

15. Carolan MS (2006) Sustainable agriculture, science and the co-production of 'expert' knowledge: the value of interactional expertise. Local Environment 11(4):421-431

16. Chambers R, Pacey A, Thrupp LA (eds) (1989) Farmer first: farmer innovation and agricultural research. Intermediate Technology Publications, London

17. Chambers R (1994) The origins and practice of participatory rural appraisal. World Development 22(7):953-969

18. Chambers R (1997) Whose reality counts? Putting the first last. ITDG Publishing, London

19. Charmaz K (2006) Constructing grounded theory: a practical guide through qualitative analysis. Sage, London

20. Cooke B, Kothari U (eds) (2001) Participation: the new tyranny? Zed Books, London

21. Corbin J, Strauss A (2015) Basics of qualitative research: techniques and procedures for developing grounded theory. Sage Publications, Thousand Oaks

22. Cuéllar-Padilla M, Calle-Collado A (2011) Can we find solutions with people? Participatory action research with small organic producers in Andalusia. Journal of Rural Studies 27:372-383

23. De Rooij, S. 2004. Young farmers in Europe: opting for innovation. LEISA INDIA Magazine on Low External Input Sustainable Agriculture 6(2):24-26.
24. De Schutter O (2010) Report submitted by the Special Rapporteur on the right to food, United Nations General Assembly, Human Rights Council, Sixteenth session, United Nations: New York

25. Edwards-Jones $G$ (2001) Should we engage in farmer-participatory research in the UK? Outlook on Agric 30(2):129-136

26. EIP-AGRI, 2020. Research needs from practice 2020. EIP-AGRI [WWW] https:// ec.europa.eu/eip/agriculture/sites/agri-eip/files/eip-agri_report_research_ needs_from_practice_2020_en.pdf (visited on 02/06/2020).

27. European Commission. 2008. Commission Regulation (EC) No 889/2008 of 5 September 2008 laying down detailed rules for the implementation of Council Regulation (EC) No 834/2007 on organic production and labelling of organic products with regard to organic production, labelling and control [WWW] https://eur-lex.europa.eu/legalcontent/EN/TXT/PDF/?uri=CELEX:32008R0889\&from=EN (visited on 03/06/2020).

28. European Commission. 2012. Communication from the Commission to the European Parliament and the Council on the European Innovation Partnership 'Agricultural Productivity and Sustainability' Brussels: European Commission [WWW] ec.europa.eu/eip/agriculture/sites/agri-eip/files/ communication_on_eip_-_en.pdf (visited on 12/06/2018).

29. European Union. 2018. Regulation (EU) 2018/848 of the European Parliament and of the Council of 30 May 2018 on organic production and labelling of organic products and repealing Council Regulation (EC) No 834/ 2007 [WWW] https://eur-lex.europa.eu/legal-content/EN/TXT/PDF/?uri= CELEX:32018R0848\&from=EN (visited on 02/06/2020).

30. Eurostat. 2016. Agriculture, forestry and fishery statistics [WWW] https://ec. europa.eu/eurostat/documents/3217494/7777899/KS-FK-16-001-EN-N.pdf/ cae3c56f-53e2-404a-9e9e-fb5f57ab49e3 (visited on 03/06/2020).

31. FAO (2016) FAOSTAT Food and agriculture data. FAO, Rome [WWW] www. fao.org/faostat (visited on 29/04/2018)

32. Flament SO, Macias B (2015) New peasants moving back to rural areas. Farming Matter 31(2):12-2

33. Flyvbjerg B (2006) Five misunderstandings about case-study research. Qual Ing 12(2):219-245

34. Fotheringham, J., Hetherington, A., Kobilsky, A., Rohmer, B., Chever, T., Renault, C., Romieu, V., Carillo, J., Giambenedetti, G., Vukovic, M., Collison, M., and Kuehnemund, M. 2016. Evaluation study of the implementation of the European Innovation Partnership for Agricultural Productivity and Sustainability. Final Report. European Commission: Brussels [WWW] https:// op.europa.eu/en/publication-detail/-/publication/3f035a53-e9dc-11e6-ad7c01aa75ed71a1 (visited on 02/06/2020).

35. Funtowicz S, Ravetz J (1993) Science for the post-normal age. Futures 25(7): 739-755

36. Gabathuler E, Bachmann F, Kläy A (2011) Reshaping rural extension. In: Learning for sustainability (LforS) - an integrative and learning-based advisory approach for rural extension with small-scale farmers. Margraf Publishers GmbH, Weikersheim

37. Gliessman SR (1995) Sustainable agriculture: an agroecological perspective. Adv Plant Pathol 11:45-57

38. Gliessman SR (2008) Agroecology: ecological processes in sustainable agriculture. Ann Arbor Press, Chelsea

39. Gomez LF, Ríos-Osorio LA, Eschenhagen-Durán ML (2016) Key concepts of agroecology science. A systematic review. Trop Subtrop Agroecosystems 19 109-117

40. Home R, Rump N (2015) Evaluation of a multi-case participatory action research project: the case of SOLINSA. The Journal of Agricultural Education and Extension 21(1):73-89

41. Gomiero T, Pimental D, Paoletti MG (2011) Environmental impact of different agricultural management practices: conventional vs. organic agriculture. Crit Rev Plant Sci 30(1-2):95-124

42. Guba EG, Lincoln YS (1994) Competing paradigms in qualitative research. In Denzin NK, Lincoln YS (eds) Handbook of qualitative research. Sage Publications, Thousand Oaks, pp 105-117

43. Guijt I, Shah MK (eds) (1998) The myth of community: gender issues in participatory development. Practical Action Publishing, England

44. Hickey S, Mohan G (2004) Participation - from tyranny to transformation. Zed Books, London

45. ISPRA (2018) Rapporto nazionale pesticidi nelle acque - dati 2015-2016. Edizione 2018. ISPRA, Roma

46. ISTAT. 2010. $6^{\circ}$ Censimento generale dell'agricoltura. ISTAT, Roma [WWW] http://censimentoagricoltura.istat.it (visited on 29/04/2018). 
47. Kajamaa A (2012) Enriching action research with the narrative approach and activity theory: analyzing the consequences of an intervention in a public sector hospital in Finland. Educational Action Research 20(1):75-93

48. Kravchenko AN, Snapp SS, Robertson GP (2017) Field-scale experiments reveal persistent yield gaps in low-input and organic cropping systems. Proceedings of the National Academy of Sciences 114(5):926-931

49. Kolb DA (1984) Experiential learning: experience as the source of learning and development. Prentice Hall, Englewood Cliffs

50. Lawrence DN, Christodoulou N, Whish J (2007) Designing better on-farm research in Australia using a participatory workshop process. Field Crops Res 104:157-164

51. Levidow L, Pimbert M, Vanloqueren G (2014) Agroecological research: conforming - or transforming the dominant agro-food regime? Agroecol Sustainable Food Syst 38(10):1127-1155

52. Lilja N, Bellon M (2008) Some common questions about participatory research: a review of the literature. Development in Practice 18(4-5):479-488

53. Lund B, Chemi T (eds) (2015) Dealing with emotions: a pedagogical challenge to innovative learning. Sense Publishers, Rotterdam

54. Meyer J (2000) Evaluating action research. Age Ageing 29(2):8-10

55. Mansuri G, Rao V (2013) Localizing development: Does Participation Work? The World Bank, Washington

56. Martin A, Sherington J (1997) Participatory research methods - implementation, effectiveness and institutional context. Agricultural Systems 55(2):195-216

57. Menconi ME, Grohmann D, Mancinelli C (2017) European farmers and participatory rural appraisal: a systematic literature review on experiences to optimize rural development. Land Use Policy 60:1-11

58. Mendez VE, Caswell M, Gliessman SR, Cohen R (2017) Integrating agroecology and participatory action research (PAR): lessons from Central America. Sustainability 9:705

59. Midgley G (2011) Theoretical pluralism in systemic action research. Systemic Practice and Action Research 24(1):1-15

60. Mier M, Cacho TG, Giraldo OF, Aldasoro M, Morales H, Ferguson BG, Rosset P, Khadse A, Campos C (2018) Bringing agroecology to scale: key drivers and emblematic cases. Agroecol Sustainable Food Syst 42(6):637-665

61. Migliorini P, Gkisakis V, Gonzalves V, Raigón MD, Bàrberi P (2018) Agroecology in Mediterranean Europe: genesis, state and perspectives. Sustainability 10(8):2724

62. Mipaaf (Ministero delle politiche agricole alimentari e forestali). 2016. Piano strategico nazionale per lo sviluppo del sistema biologico [WWW] https:// www.politicheagricole.it/flex/cm/pages/ServeBLOB.php/L/IT/IDPagina/10014 (visited on 12/06/2018).

63. Mosse D (2004) Cultivating development: an ethnography of aid policy and practice. Pluto Press, London

64. Mukute M, Lotz-Sisitka H (2012) Working with cultural-historical activity theory and critical realism to investigate and expand farmer learning in Southern Africa. Mind, Culture, and Activity 19:342-367

65. Nabasa J, Rutwara G, Walker F, Were C (1995) Participatory rural appraisal: principles and practicalities. Natural Resources Institute, Chatam

66. Olagnero M (2005) Vite nel tempo. La ricerca biografica in sociologia. Carocci, Roma

67. Oliver B (2016) "The earth gives us so much": agroecology and rural women's leadership in Uruguay. Cult Agric Food Environ 38(1):38-47

68. Organic Action Network Italia. 2017. Carta del biologico di Bergamo. II modello biologico per una produzione agricola e un consumo sostenibili. Organic Action Network Italia [WWW] http://www.anabio.it/uploads/article/ cartadelbiologicodibergamo-92d8dfefbd.pdf (visited on 29/04/2018).

69. Orlando F, Alali S, Vaglia V, Pagliarino E, Bacenetti J, Bocchi S (2020) Participatory approach for developing knowledge on organic rice farming: management strategies and productive performance. Agric Syst 178:102739

70. Ortolani L, Bocci R, Bàrberi P, Howlett S, Chable V (2017) Changes in knowledge management strategies can support emerging innovative actors in organic agriculture: the case of participatory plant breeding in Europe. Org Farming 3(1):20-33

71. Padel S (2001) Conversion to organic farming: a typical example of the diffusion of an innovation? Sociologia Ruralis 41(1):40-61

72. Patel $R$ (2012) The long green revolution. J Peasant Stud 40(1):1-63

73. Pence RA, Grieshop JI (2001) Mapping the road for voluntary change: partnerships in agricultural extension. Agric Hum Values 18(2):209-217

74. Phillips M, Dickie J (2014) Narratives of transition/non-transition towards low carbon futures within English rural communities. J Rural Stud 34:79-95

75. Pimbert M (2009) Towards food sovereignty: reclaiming autonomous food systems. International Institute of Environment and Development, London
76. Pound B, Snapp S, McDougall C, Braun A (eds) (2003) Managing natural resources for sustainable livelihoods: uniting science and participation. Earthscan Publications, London

77. Pretty NJ (1995) Participatory learning for sustainable agriculture. World Development 23(8):1247-1263

78. Pretty J (2002) Agri-culture: reconnecting people, land and nature. Earthscan Publications, London

79. Ragin CC, Becker HS (eds) (1992) What is a case? Exploring the foundations of social inquiry. Cambridge University Press, Cambridge

80. Reganold JP, Wachter JM (2016) Organic agriculture in the twenty-first century. Nature Plants 2(2):15221

81. Röling N (1988) Extension science: information systems in agricultural development. Cambridge University Press, New York

82. Röling N, Engel P (1990) The development of the concept of agricultural knowledge information systems (AKIS): implications for extension. In: Rivera WM, Gustafson DJ (eds) Agricultural extension: Worldwide institutional evolution and forces for challenge. Elsevier, Amsterdam

83. Röling N, Jiggins J (1998) The ecological knowledge system. In: Röling N, Wagemakers MAE (eds) Facilitating sustainable agriculture: Participatory learning and adaptive management in times of environmental uncertainty. Cambridge University Press, Cambridge

84. Röling N, Wagemakers MAE (eds) (1998) Facilitating sustainable agriculture: participatory learning and adaptive management in times of environmental uncertainty. Cambridge University Press, Cambridge

85. Romani M, Beltarre G, Tabacchi M (2007) Organic rice farming. Regione Lombardia, Milan

86. Savin-Baden M, Van Niekerk L (2007) Narrative inquiry: theory and practice. J Geogr High Educ 31(3):459-472

87. Sevilla-Guzmán E, Woodgate G (1997) Sustainable rural development: from industrial agriculture to agroecology. In: Redclift M, Woodgate G (eds) The international handbook of environmental sociology. Edward Elgar, Cheltenham

88. Shennan C, Krupnik TJ, Baird G, Cohen H, Forbush K, Lovell RJ, Olimpi EM (2017) Organic and conventional agriculture: a useful framing? Annual Review of Environment and Resources 42:317-346

89. Siciliano E (1998) Approccio biografico. In: Melucci A (ed) Verso una sociologia riflessiva. II Mulino, Bologna

90. Stake RE (1995) The art of case study research. Sage Publications, Thousand Oaks

91. Tilman D, Cassman KG, Matson PA, Naylor R, Polasky S (2002) Agricultural sustainability and intensive production practices. Nature 418:671-677

92. Tracy SJ (2010) Qualitative quality: eight "big-tent" criteria for excellent qualitative research. Qualitative Inquiry 16(10):837-851

93. United Nations. 2015. Transforming our world: the 2030 agenda for sustainable development [WWW] https://sustainabledevelopment.un.org/ content/documents/21252030\%20Agenda\%20for\%20Sustainable\%2 ODevelopment\%20web.pdf (visited on 5/4/2018)

94. Uphoff N (ed) (2002) Agroecological innovations: increasing food production with participatory development. Earthscan Publications, London

95. Von Münchhausen S, Häring AM (2012) Lifelong learning for farmers: enhancing competitiveness, knowledge transfer and innovation in the eastern German state of Brandenburg. Stud Agric Econ 114:86-92

96. Warner KD (2008) Agroecology as participatory science emerging alternatives to technology transfer extension practice. Sci Technol Hum Val 33(6):754-777

97. Wezel A, Bellon S, Dore T, Francis C, Vallod D, David C (2009) Agroecology as a science, a movement and a practice. A review. Agronomy Sustainable Dev 29:503-515

98. Wezel A, Goette J, Lagneaux E, Passuello G, Reisman E, Rodier C, Turpin G (2018) Agroecology in Europe: research, education, collective action networks, and alternative food systems. Sustainability 10:1214

99. Zuber-Skerrit O (2001) Action learning and action research: paradigm, praxis and programs. In: Sankara S, Dick B, Passfield R (eds) Effective Change Management through Action Research and Action Learning: Concepts, Perspectives. Processes and Applications. Southern Cross University Press, Lismore, pp 1-20

\section{Publisher's Note}

Springer Nature remains neutral with regard to jurisdictional claims in published maps and institutional affiliations. 